\title{
CORRESPONDENCE
}

\section{Levalbuterol toxicity: no reason to be jittery}

\section{To the Editor:}

Levalbuterol, the $\mathrm{R}$-isomer of racemic albuterol, is a more effective bronchodilator with fewer side-effects than racemic albuterol [1-3]. We present a paediatric patient in status asthmaticus who received twelve times the prescribed dose of levalbuterol and manifested only mild systemic side-effects.

This 4-yr-old African-American male was admitted to the Pediatric Intensive Care Unit (Portsmouth, VA, USA) where continuous nebulised levalbuterol was ordered at $0.63 \mathrm{mg} \cdot \mathrm{h}^{-1}$. The nebuliser chamber was erroneously filled with twelve $0.63 \mathrm{mg}$ unit-dose ampoules, delivering $7.56 \mathrm{mg} \cdot \mathrm{h}^{-1}$ of levalbuterol. This dosing regimen was continued for twelve hours before it was discovered.

On the morning rounds, the child was noted to be tachypneic and tachycardic, with a respiratory rate in the mid 40s and cardiac frequency in the range of $150-170$ beats $\cdot \mathrm{min}^{-1}$. Oxygen saturation was $97-100 \%$ on an inspiratory oxygen fraction of 0.3 . The patient was sleeping without any respiratory difficulty. The levalbuterol dose was reduced to $1.25 \mathrm{mg} \cdot \mathrm{h}^{-1}$ and serum electrolytes were obtained. These were completely within normal limits, including potassium of $4.0 \mathrm{mmol} \cdot \mathrm{L}^{-1}$. The patient was weaned off continuous nebuliser treatments over the following $8 \mathrm{~h}$ and was transferred to the paediatric ward the next day. The remainder of his hospital course was without incident and he was discharged in good condition.

Racemic albuterol contains both R-albuterol (levalbuterol), which has bronchodilatory activity, and S-levalbuterol, initially thought to be inert. Studies have demonstrated that the $\mathrm{S}$-levalbuterol not only increases intracellular-free calcium, which is an agonist in airway smooth muscle contraction, but also has significant proinflammatory effects, including increasing the production of histamine and interleukin-4 in mast cells [3-5]. These results support the concept that the S-levalbuterol may have significant detrimental effects on pulmonary function in an acute asthma exacerbation. Reported side-effects of levalbuterol in the studies of both NELSON et al. [1] and GAWCHIK et al. [2] included increased heart frequency, tremor and hypokalaemia that were dose related but similar between the two study groups.

In the intensive care unit (ICU) setting, dosing of racemic albuterol as high as $20 \mathrm{mg} \cdot \mathrm{h}^{-1}$ in children with status asthmaticus is not uncommon. However, therapeutic dosing of levalbuterol in asthmatics at $>1.25 \mathrm{mg}$ has not been previously reported. Tremor, heart rate and hypokalaemia were dose related following inhalation of increasing doses of levalbuterol (0.2-3.2 mg) in normal volunteers. However, our patient received a dose twice that given to these volunteers and experienced only minimal side-effects.
We also believe that this may be the first report on the use of continuous levalbuterol nebulisation in an inpatient setting for children. The National Asthma Education Program, Expert Panel Report: Guidelines for the Diagnosis and Management of Asthma-No. 91-3042, recommended using racemic albuterol up to every $1-2 \mathrm{~h}$ for moderately ill children and continuous nebulisation for severely ill children in the ICU setting. Our dosing guideline was based upon these recommendations and previous studies, suggesting levalbuterol at $0.63 \mathrm{mg}$ as the starting dose and escalating to $1.25 \mathrm{mg}$ if necessary $[1,2]$.

This case illustrates that the safety profile for levalbuterol may be more generous in paediatric patients than previously reported. Furthermore, continuous nebulised levalbuterol can be easily and safely delivered in the intensive care unit setting, both to intubated and nonintubated patients. However, we suggest further studies with other levalbuterol dosing regimens should be conducted before there is widespread use of doses $>1.25 \mathrm{mg}$.

\section{A.K. Biswas*, W.C. Fruedenthal ${ }^{\#}$}

Depts of $*$ Critical Care Medicine, Division of Pediatric Critical Care Medicine and ${ }^{\#}$ Emergency Medicine, Naval Medical Center Portsmouth, Portsmouth, VA, USA.

\section{References}

1. Nelson HS, Bensch G, Pleskow WW, et al. Improved bronchodilation with levalbuterol compared with racemic albuterol in patients with asthma. J Allergy Clin Immunol 1998; 102: 943-952.

2. Gawchik SM, Saccar CL, Noonan M, Reasner DS, DeGraw SS. The safety and efficacy of nebulized levalbuterol compared with racemic albuterol and placebo in the treatment of asthma in pediatric patients. J Allergy Clin Immunol 1999; 103: 615-621.

3. Mitra S, Ugur M, Ugur O, Goodman HM, McCullough JR, Yamaguchi H. (S)-albuterol increases intracellular free calcium by muscarinic receptor activation and a phospholipase C-dependent mechanism in airway smooth muscle. Mol Pharm 1998; 53: 347-354.

4. Volcheck GW, Gleich GJ, Kita H. Pro- and anti-inflammatory effects of beta adrenergic agonists on eosinophil response to IL-5. J Allergy Clin Immunol 1998; 101: S35.

5. Cho SH, Hartleroad JY, Oh CK. (S)-albuterol increases the production of histamine and IL-4 in mast cells. Int Arch Allergy Immunol 2001; 124: 478-484. 